\title{
Editorial
}

\section{Rights and property paradigms: challenging the dominant construct hegemony}

The interrelationship of (human) rights and property paradigms raises particularly profound questions when played out in respect of environmental claims. It is therefore no surprise that contributions to this edition invoke ontological and epistemological concerns fundamental to the unsettled interface between the mutable richness of living spatial and socio-cultural ecologies and the abrupt reductionisms so often imposed upon them by law. At the same time it speaks of the power and dominance of property paradigms that even the most critical analyses tend to seek reformulation of property's parameters rather than its abandonment.

Multiple critical accounts of the legal order suggest that Western conceptions of 'rights' and 'property' suppose an idealized (or even fictitious) 'even' juridical field within which putatively equal actors negotiate entitlements. This characterization of property carves out the rights of a 'subject' over a world constructed as 'object' and is pressed into service in the name of 'progress' as an approach which both produces and strategically denies the fundamentally differentiated ability to access rights lying at the foundations of the legal order. While this view of property should not be overstated (for there are contradictory currents and multiple nuances within Western property concepts and law, as the articles by Grear, Layard and Pieraccini in this edition suggest) it does offer a valuable insight into the underlying exploitative visions of interhuman and human-environmental relations upon which it rests. It is therefore no coincidence that some of the most intractably complex questions concerning the nature of rights and property - and the project to redefine/expand its meaning - centre on spaces and places in which alternative ontologies and epistemologies come to the fore.

Grear argues that there is a 'productive' ambivalence in both human rights and property, attention to which is fundamental for an adequate understanding of the relationship between them in the nexus between human rights and the environment. She explores the elusiveness and contestability exhibited by human rights, pointing to the range of critiques to which they are subject. She points to the fact that these accounts are ultimately united by an attempt to expose, resist and/or replace the ontological suppositions lying at the foundations of Western narratives of 'progress', private property and the unsustainable capitalist exploitation of natural resources. This analysis questions the assumption that human rights are necessarily inclusory limits on exclusory property claims. Grear argues that it is important to appreciate the relationship between human rights and property in terms of a shared ambivalence reflecting their mutual openness to conflicting impulses of oppression and emancipation. In particular, she argues that property, despite its mainstream formulation as predominantly exclusive, can be theorized in such a way as to render it open to alternative readings. Contested claims relating to the nature of property, in Grear's view, provide a creative space to exploit the 'ambivalence' of the concept itself, suggesting a 'productive' instability. 
Grear argues that property should be reconceived as a claim for access and inclusion in relation to the fundamental goods of life but goes further, arguing that such an inclusory re-imagination of property urgently requires new ontological foundations if property is to perform a transformative role in the search for 'worlds other' and for an 'eco-humane' future.

It is a central implication of Grear's argument that while the Western rights and property paradigm presupposes a unitary subject around whom the world turns as 'environment', there are of course other modes of knowing, frequently suppressed by the dominant paradigm, by which communities, persons and world are co-formed and in which the 'environment' is not a mere context for the human. These alternative understandings can also be found in more subtle forms even within the interstices of the dominant property paradigm in the West (as the contributions of Pieraccini and Layard imply), but notwithstanding nuanced counter-hegemonic impulses, it is apparent that the influence of Western ontology and epistemology and its subject-object relations throughout the world has facilitated the spread of commerce-driven property dynamics. These in turn have resulted in the erasure of Indigenous ways of life (and indeed of entire cultures and races), mass extinction of other species and widespread eco-system degradation. At the heart of Birrell, Godden and Tehan's contribution is a concern centring upon the spectre of neo-colonialism, enhanced by the endorsement of national governments in the developing world - this time reflected by carbon markets and the as-yet unreconciled tensions between such schemes and Indigenous and local community interests, rights and traditional knowledge. Focusing on the Reducing Emissions from Deforestation and Degradation (REDD/REDD+) scheme, the authors point to potential impacts on the 'property' rights and interests of Indigenous communities. They therefore argue that the pace of and enthusiasm for investment in and implementation of REDD requires close scrutiny. The potential of this global project to co-opt Indigenous and local community interests and exclude local inhabitants of forested areas from the value of carbon 'offset' leads the authors to raise a series of fundamental questions concerning conflicts between differing conceptions of property. Fundamental ontological tensions are in play here, with Indigenous and non-Indigenous conceptions of property, including systems of formal and informal tenure, continuing to collide in a complex environment where States tend to favour Western-style property models that facilitate the misappropriation of Indigenous lands and associated rights in the name of environmental protection. The result is that REDD could simply embed (or perhaps, re-embed) Western models of value assignment (subsumed beneath legal designations of 'property') in a type of replication of colonial patterns. 'These tensions', suggest the authors, 'highlight the potential schism between the achievements of environmental/ climate change mitigation objectives and the retention of Indigenous and customary communal property forms' suggesting that new forms of cultural eradication remain an ever-present possibility. The authors argue for the adoption of approaches and innovative legal mechanisms which address Indigenous peoples' knowledge of and capacity to contribute to climate change mitigation that also provide tangible benefits to themselves. The authors also underline the need for constant vigilance to ensure that REDD/REDD+ "is not merely the latest wave in a continuing tide of "deep" colonization of the life spaces of Indigenous peoples'.

The 'colonization' of Indigenous lands and associated rights by States and commercial actors is also present in Kamphuis's contribution, which traces a violent narrative of deception, fraud, overt force and juridical inhumanity in Peru. Kamphuis charts a case in which Indigenous communities are overtly threatened by a mining corporation exploiting an insidious and oppressive convergence between public and private 
power in employing a privatized and privatizing set of property imperatives. Her account examines the effects of a convergence between the private power of Yanacocha Mine and the Peruvian State's public power as they forge something close to an alliance that is exerting an almost inexorable logic of neo-liberal appropriation of two interrelated 'sites of power': Indigenous land rights and the regulation of the use of force. By tracking two international human rights litigation initiatives (the Negritos Case and the GRUFIDES Case) Kamphuis seeks to illustrate the complex relationship between Peru's colonial history, Yanacocha's commercial power and influence on national affairs and the resulting, serious land rights violations, the emergence of widespread social protest, and an escalating use of private security companies by multinational mining companies. She also highlights state police complicity in deceptive and violent tactics of the appropriation of Indigenous life spaces, identifying four legal processes as pivotal: the privatization of Indigenous land; the production (though 'manufacture' may be more apt) of Indigenous consent; the privatization of coercive force; and the absence of effective legal remedies. The case study, Kamphuis suggests, may hold valuable lessons for those seeking to use the law to engage in practices of resistance to the power configuration represented by private-public convergence.

Forms of private-public convergence emerge in a very different context in Layard's account of the 'colonization' of public spaces by private actors and the interplay between hegemonic understandings of property and alternative understandings of relationships with place and space. Layard's concern is with the relationship between property paradigms, place-making, and the 'right to the street' - specifically, the idea of reclaiming the streets - including for play. Layard's questions concerning the reclamation of British streets may seem to raise matters of relatively minor concern, at first glance, compared to questions concerning the violence of Indigenous exclusion from their lands, but in reality they raise similar underlying themes. Layard's account, for example, suggests again the fundamental dissonance between hegemonic conceptions of property and alternative visions of place-making and of social and spatial ecologies - including those of children. Layard's review of the 'human right to the city', as a social and a spatial claim sensitive to cultural and environmental realities, underlines its general articulation as a rhetorical strategy and places this in direct relationship with an analysis of the use of highways as routes for passage. We could, she suggests, allow greater local control of non-arterial roads and passages, moving from the dominance of 'routes' to an emphasis upon 'roots' and to streets as spaces of alternate modes of being. The argument here echoes the ontological dissonance emerging in Birrell, Godden and Tehan, and in Kamphuis's accounts of relationships between rights and property paradigms. The convergence of public and private power, such a central concern for Kamphuis, also emerges in a more subtle form in Layard's account. She identifies the exclusory construction of city space, noting the 'increasing rolling up of city centres into large privately owned enclaves of many, many acres ... accessible only to "visitors", not citizens'. These access concerns parallel Gray's passionate advocacy of 'pedestrian democracy' in the first edition of the Journal of Human Rights and the Environment but centres on the question of whether in the extensive "now private, previously public, spaces local residents and citizens still have "the most encompassing right to 'be' in the city as a totality". 1

All of the contributions to this edition intimate the ontological and epistemological closures implicated in Western constructions of property and the interplay between

1. A Kirby, 'The Production of Private Space and its Implications for Urban Social Relations' (2008) 27 Political Geography 74, 91. 
different modes of being and knowing as human beings in places, spaces and ecologies. Pieraccini also takes this tack, examining interacting property impulses in the law of England and Wales through the lens of conservation law. She uses this to scrutinize the relationship between rights and property paradigms, insisting that property is always a relational concept but that the ways in which this unfolds are not uniform. Pieraccini's chosen contrast is between two property paradigms: the 'socio-legal' and 'ecological'. Pieraccini views the socio-legal paradigm as primarily anthropocentric but also as demonstrating nuances that are critical of the Western conceptions of property in so far as it promotes the notion of property as stewardship. The ecological paradigm, meanwhile, is anchored in phenomenological thought and emphasizes 'practices, movement and dwelling' and the ecologically-embedded nature of property by 'defining property as the contingent product of humans and non-human animals' interactions with the land'. For Pieraccini, conservation law is guided by the 'socio-legal' paradigm, yet its regulatory interaction is with land and relationships marked by an ecologicallyembedded conception of property. The meaning of property here too is contestable and certain visions of property, notably those more sensitive to living interaction, are marginalized by the law. Pieraccini suggests that this is fundamentally problematic from an environmental point of view, showing that, without full acknowledgement of the presence of both meanings of property in the context of common land in England and Wales, conservation law cannot be fully effective. Pieraccini also brings these issues into direct analytical contact with property pluralism and its implications for the idea of property as a human right, concluding that, at least in the context of conservation law in England and Wales, adopting reflexive elements in conservation law can potentially effect a reconciliation between the socio-legal and ecological paradigms of property.

Karen Morrow (Co-Editor in Chief) Centre for Environment and Energy Law and Policy, Swansea University, UK and

GNHRE core team member

Anna Grear (Co-Editor in Chief) Associate Professor of Law, University of Waikato, New Zealand and Director, Global Network for the Study of Human Rights and the Environment (GNHRE) 